\title{
Study on the Performance of Adjustable Platform Screen Door in Subway Stations
}

\author{
Su Ziyi ${ }^{1, *}$, Li Xiaofeng ${ }^{1}$, and Zhang Yue ${ }^{1}$ \\ ${ }^{1}$ Department of Building Science, School of Architecture, Tsinghua University, China
}

\begin{abstract}
In the last decades, the construction of subway systems has been in rapid progress in metropolis. Former studies have pointed out that substantial amount of energy is consumed by subway stations. Thus, the adjustable platform screen door (APSD) system is widely adopted, which is characterized by the energysaving in both the cooling season and the transitional season. However, the installation of APSD system might result in thermal discomfort for passengers, which lacks investigation. This study aims to study the performance on the thermal comfort of subway station with APSD system. In this process, Computational Fluid Dynamics (CFD) Simulation was conducted using PHOENICS to obtain the velocity and temperature distribution under 3 kinds of train arrival patterns. Furthermore, Relative Warmth Index (RWI) was used to assess thermal comfort. The results show that the velocities of the platform and station hall are below $2.5 \mathrm{~m} / \mathrm{s}$ and $3.7 \mathrm{~m} / \mathrm{s}$ respectively, which is closely related to the train arrival pattern. With regard to the platform occupied zone, the RWI is between 0.04 to 0.19 , which is almost within the thermal comfort zone according to the ASHRAE comfort classification. Nevertheless, for the occupied zone of the hall, the RWI is between 0.15 to 0.52 , indicating relatively warm.
\end{abstract}

\section{Introduction}

Nowadays, with the rapid economic development, more and more cities are equipped with the subway system to improve urban infrastructure. Take China for an example, by the end of 2018, a total of $5761 \mathrm{~km}$ subway lines was constructed and put into use, covering 35 cities nationwide and accounting for $75.6 \%$ of the urban rail transit system. In the meantime, the number of passengers transported has reached 21.07 billion per year, increasing $14 \%$ compared with previous years ${ }^{[1]}$.

The energy consumption of subway station is much higher than that of other types of public buildings due to the long operation time, intensive train timetable and high passenger density. It is widely acknowledged that platform screen door system is energy-saving in the cooling season, whereas the security door system is energy-saving in the ventilation conditions [2,3]. Currently, the adjustable platform screen door (APSD) system is widely applied in actual projects due to its energy-saving characteristics in consideration of the whole year ${ }^{[4-6]}$, the operation mode of which can be switched between the ventilation and closed mode. The commonly used form of APSD is shown in Fig.1, which is composed of the fixed door, sliding door and the vent on the top.

During the transitional season, the vent of the APSD system can be opened and therefore the train-induced air flow of the tunnel can be utilized to provide "free cooling" for the platform. However, with the opening of the APSD vent, the air velocity of the station tends to increase significantly, which may bring discomfort to the passengers. Therefore, it is significant to investigate thermal comfort of the station with APSD system.

This paper aims to study the thermal comfort for subway stations with the commonly-applied APSD system under the ventilation mode. In the field of thermal comfort research, CFD simulation is a widely adopted method ${ }^{[7-13]}$, which is also used in this study.

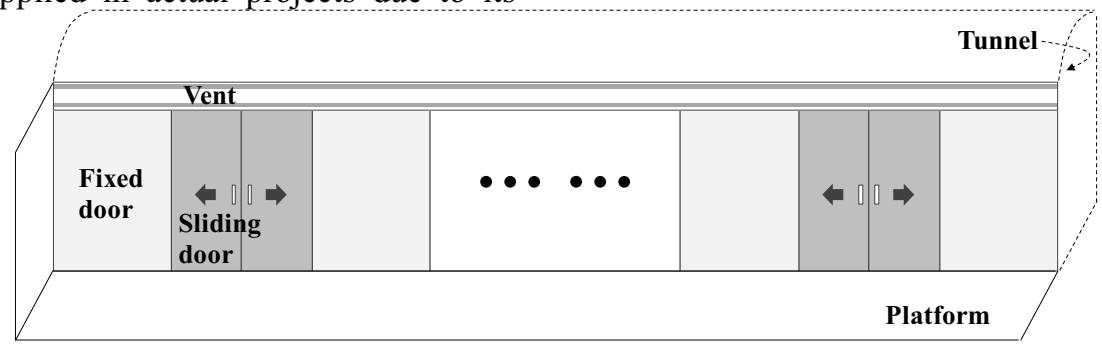

Fig. 1. Schematic of APSD system

\footnotetext{
$\overline{\text { * Corresponding author: su-zy@foxmail.com }}$
} 
Table 1. Station Load.

\section{Simulation Method}

\subsection{Case Study}

The case study was an actual island subway station located in the hot-summer and cold-winter region in China. The outside air temperature is $15^{\circ} \mathrm{C}$ and the tunnel air temperature is $20^{\circ} \mathrm{C}$, which is set to the typical condition for rush hours.

Three commonly-occurred train arrival patterns are taken into account, including bilateral train arriving, unilateral train arriving, and one arriving one leaving, as shown in Fig.2.

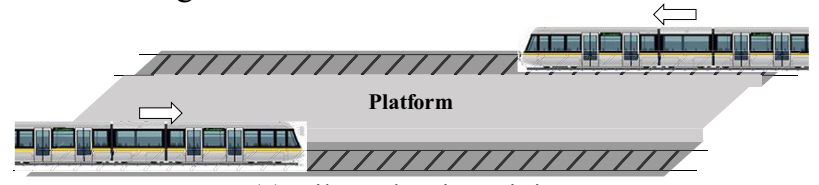

(a) Bilateral train arriving

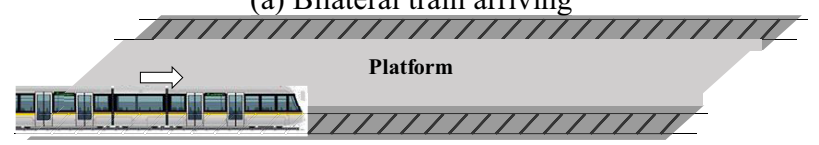

(b) Unilateral train arriving

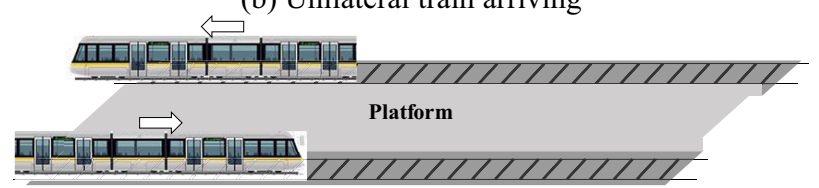

(c) One arriving One leaving

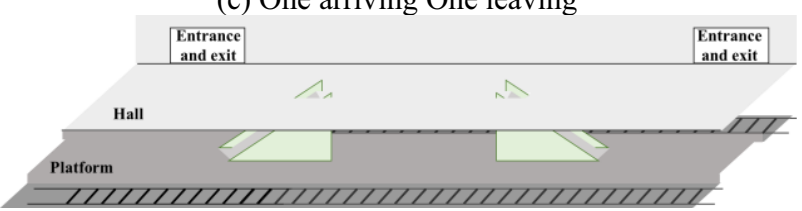

(d) schematic of the hall and platform (without APSD)

Fig. 2. Schematic of the station and 3 arrival patterns

\subsection{Numerical Model}

The model was established in the CFD package PHOENICS. PHOENICS solves the conservation equations of air mass, momentum, energy, concentration, kinetic energy and dissipation rate of kinetic energy ${ }^{[14]}$. In this study, simulation was conducted in PHOENICS to obtain the velocity and temperature distribution for the platform and station hall, under the above-mentioned 3 kinds of train arrival patterns.

\subsubsection{Geometry}

The simulation domain is $154 \mathrm{~m}$ in the length, $17.8 \mathrm{~m}$ in the width and $11 \mathrm{~m}$ in the height, which is composed of tunnel, platform, hall, and other structures. All the surfaces are assumed to be adiabatic. The cooling loads for the platform and the hall can be obtained using the theoretical model ${ }^{[15]}$. In this model, the cooling load of the station is composed of the heat dissipation of the passengers and station devices. The results are presented in Table 1 , which are $19.3 \mathrm{~kW}$ and $25.0 \mathrm{~kW}$ for the platform and hall, respectively.

\begin{tabular}{|c|c|c|}
\hline Station Load & Platform & Hall \\
\hline Passenger & $12.8 \mathrm{~kW}$ & $9.8 \mathrm{~kW}$ \\
\hline Elevator & $1.1 \mathrm{~kW}$ & $6.9 \mathrm{~kW}$ \\
\hline Lighting and Devices & $5.4 \mathrm{~kW}$ & $8.3 \mathrm{~kW}$ \\
\hline Total & $19.3 \mathrm{~kW}$ & $25.0 \mathrm{~kW}$ \\
\hline
\end{tabular}

\subsubsection{Boundary Condition}

There are 4 outlets in the hall layer, the boundary conditions of which are set as atmospheric pressure and temperature. And there are 4 inlets in the tunnel, as is numbered 1-4 in Fig.3. The inputs of the 4 inlets are tunnel air velocity and temperature. The CFD dynamic mesh model with the movement of the train is characterized by the complex calculation as well as timeconsuming. Therefore, the tunnel air velocity is obtained via Subway Thermal Environment Simulation Software (STESS) ${ }^{[16]}$. The results of the STESS simulation for the 3 types of train arrival patterns are shown in Fig.4. The train arriving process corresponds to $60-90 \mathrm{~s}$ and the train stopped condition corresponds to 120-150s in Fig.4.

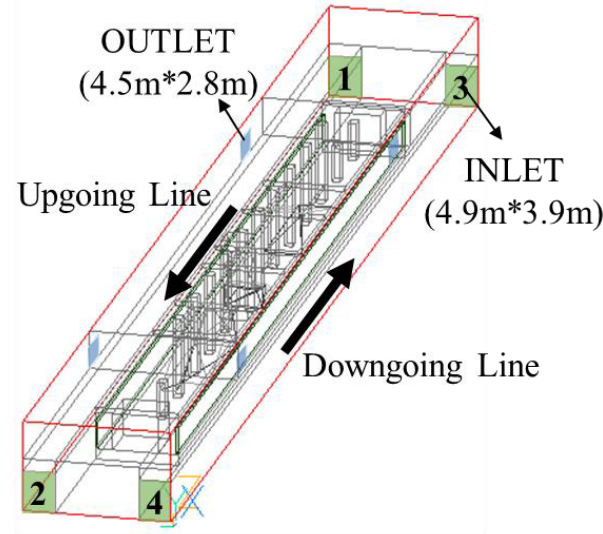

Fig. 3. The 4 inlets in the tunnel

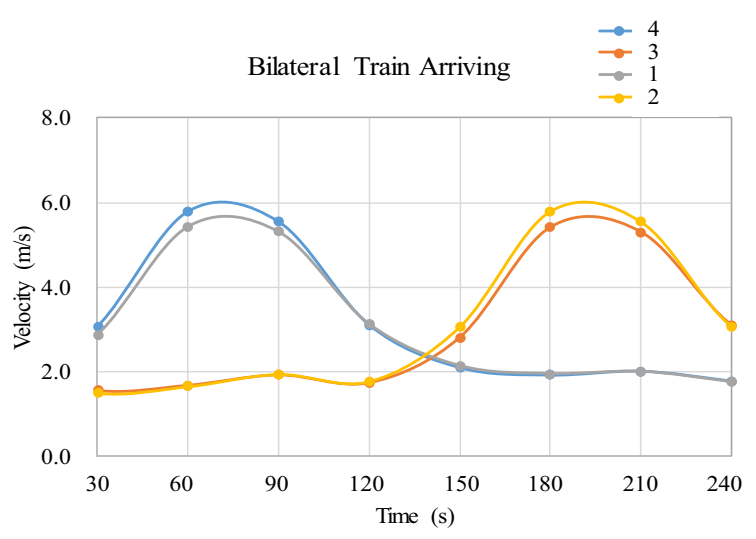

(a) Bilateral train arriving 


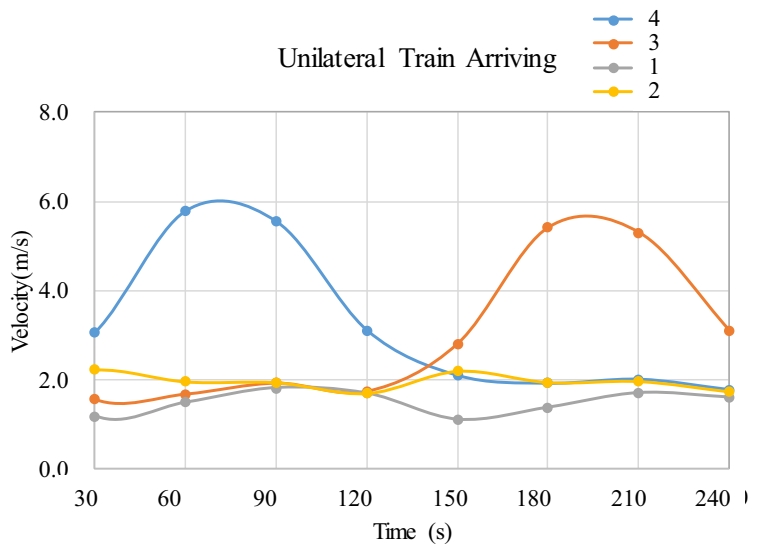

(b) Unilateral train arriving

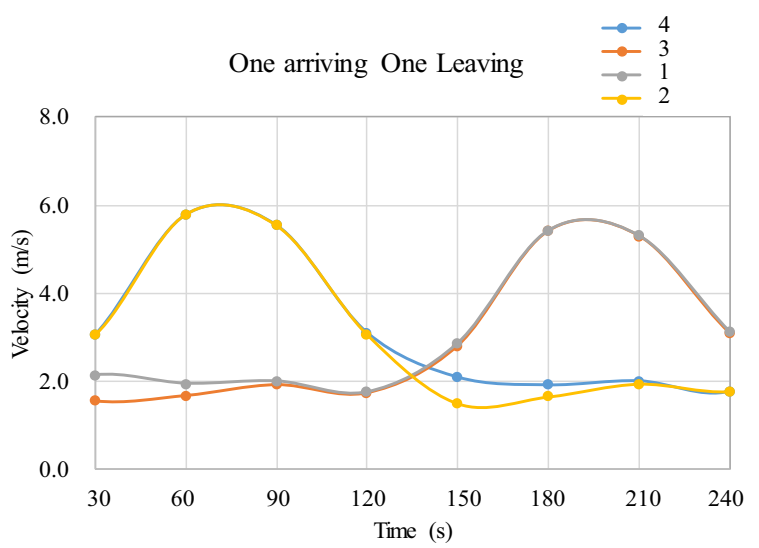

(c) One arriving One leaving

Fig. 4. Results of STESS simulation

\subsubsection{Numerical Settings}

The simulation was carried out by PHOENICS. The KERNG turbulence model was adopted in this study. The wall function is set as LOG-LAW, which is suitable for the surfaces inside the building. With the aim to simulate different conditions caused by the piston effect, the time step was set to $30 \mathrm{~s}$ and the duration was set to 240 s, which contains the period for train arriving, train stopped and train leaving. By using the boundary conditions sets in Fig.4, a collection of steady state CFD simulations was conducted. The number of iterations is set as 1000 .

\subsubsection{Grid Independence Test}

The grid settings influence the simulation time and accuracy significantly. The grid independence was verified by simulating the air flow for the 3 grid configurations made of $165,000,449,996$ and 880,968 respectively. The detailed information of the 3 kinds of grid are listed in Table 2.

The temperature and velocity distributions of the aforementioned three kinds of grid settings are compared, both for the vertical plane and for the horizontal plane. It can be concluded from Fig.5 that compared with Grid 3, the temperature and velocity difference for Grid 1 are $0.32^{\circ} \mathrm{C}$ and $0.31 \mathrm{~m} / \mathrm{s}$ respectively, whereas the temperature and velocity difference for Grid 2 are $0.16^{\circ} \mathrm{C}$ and $0.05 \mathrm{~m} / \mathrm{s}$ respectively. Thus, Grid 2 is eventually decided to be set for the following simulations, with 449,996 grids in total.

Table 2. Three kinds of grid for Grid Independence Test.

\begin{tabular}{|c|c|c|c|}
\hline Number of grids & Grid 1 & Grid 2 & Grid 3 \\
\hline X-Direction & 150 & 191 & 264 \\
\hline Y-Direction & 44 & 62 & 71 \\
\hline Z-Direction & 25 & 38 & 47 \\
\hline Total & 165,000 & 449,996 & 880,968 \\
\hline
\end{tabular}
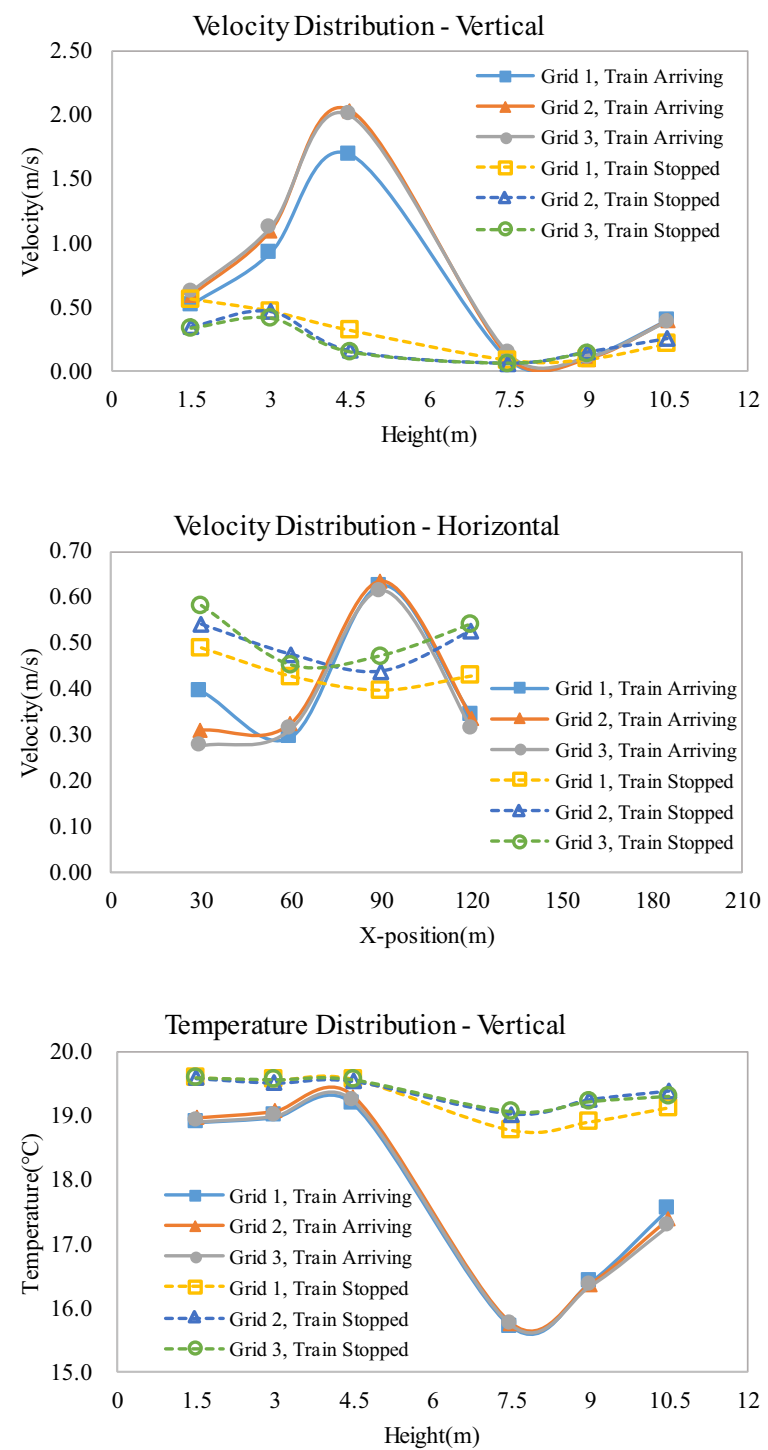


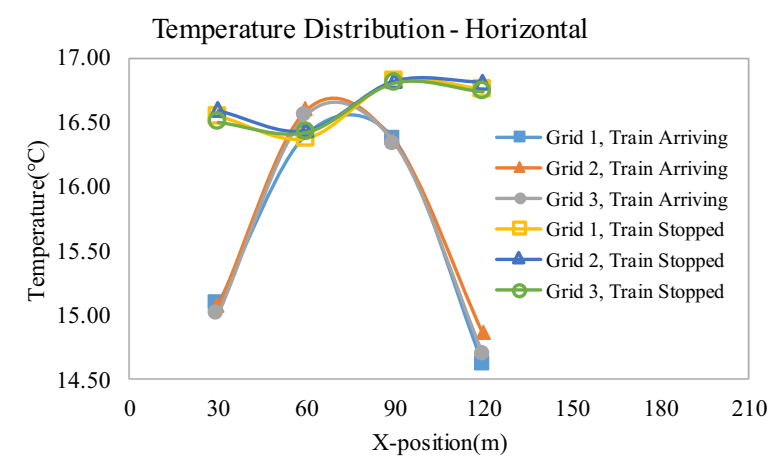

Fig. 5. Results of grid independence test

\subsection{Validation}

The simulation model was validated by comparing with the measurement data. The field testing is placed at four entrances and exits of the station hall. The Mean Bias Error (MBE) for the simulation data is $18 \%$, which is considered acceptable according to similar researches $[17,18]$.

\section{Evaluation Indices}

Relative Warmth Index (RWI) is the recommended index for occupant thermal comfort evaluation of subway stations, which was proposed by the United States Department of Transportation in $1976{ }^{[19]}$. Considering the underground location and environmental condition of subway stations, the calculation equation of RWI is as follows.

$$
\begin{gathered}
R W I=\frac{M\left(I_{c w}+I_{a}\right)+6.42(t-35)}{234} \\
I_{a}=0.0392 v_{a}^{-0.4294}
\end{gathered}
$$

where $M$ is the metabolic rate, set to $123 \mathrm{~W} / \mathrm{m}^{2} ; I_{c w}$ is insulation of clothing based on wet cloth assumption, set to $0.4 \mathrm{clo} ; I_{a}$ is insulation effect of air boundary layer, clo; $t$ is the dry-bulb air temperature, ${ }^{\circ} \mathrm{C} ; v_{a}$ is taken as air velocity, $\mathrm{m} / \mathrm{s}$.

\section{Results and Comparison}

\subsection{Velocity and Temperature Distribution}

The platform and hall velocity distribution when the train is arriving under the 3 patterns are shown in Fig.6. The train arrival pattern, which causes different strength of the piston effect, exerts strong effect on the velocity distribution both for the platform and the station hall. Higher air velocity tends to present near the stairway as well as the entrance and exit of the station. The maximum air velocities of the platform under 3 different train arrival patterns range from $2.2 \mathrm{~m} / \mathrm{s}$ to $2.5 \mathrm{~m} / \mathrm{s}$. However, it can be concluded from the platform air velocity distribution that the piston effect is strengthened by the bilateral train arrival pattern and one arriving one leaving pattern, resulting in higher overall platform air velocity. For the station hall, the regularity of strengthened piston effect is also applicable. However, the maximum air velocities for the 3 patterns range from $1.8 \mathrm{~m} / \mathrm{s}$ to $3.7 \mathrm{~m} / \mathrm{s}$, which are quite different. For the station hall, it can be concluded that the air velocity distribution under bilateral train arrival pattern is significantly higher than that under the other two conditions, which could be illustrated by that the counteraction of piston effect between the platform and tunnels is weaker, resulting in the overall higher air velocity in the station hall. And the velocity results for the train stopped condition is shown in Fig.7. The values for the 3 patterns are much lower.

The temperature distribution is also greatly affect by piston effect. Fig. 8 gives the platform and hall temperature distribution when the train is arriving under the 3 patterns. Under the bilateral train arrival pattern, a large amount of tunnel air flows to the outside through the platform and station hall, and therefore the overall temperature of the station is close to the tunnel temperature. For the unilateral train arrival pattern, the piston effect is weaker, as a result of which, only the platform temperature is similar to the tunnel temperature, whereas the station hall temperature is also affected by the outdoor temperature. For the one arrival one leaving pattern, the piston effect has a strong counteraction between the platform and the tunnel. Thus, the platform temperature is affected both by the outdoor and by the tunnel temperature, whereas the temperature of the station hall is mainly affected by the outdoor temperature. And the temperature results for the train stopped condition is shown in Fig.9, which is relevant to the former. 


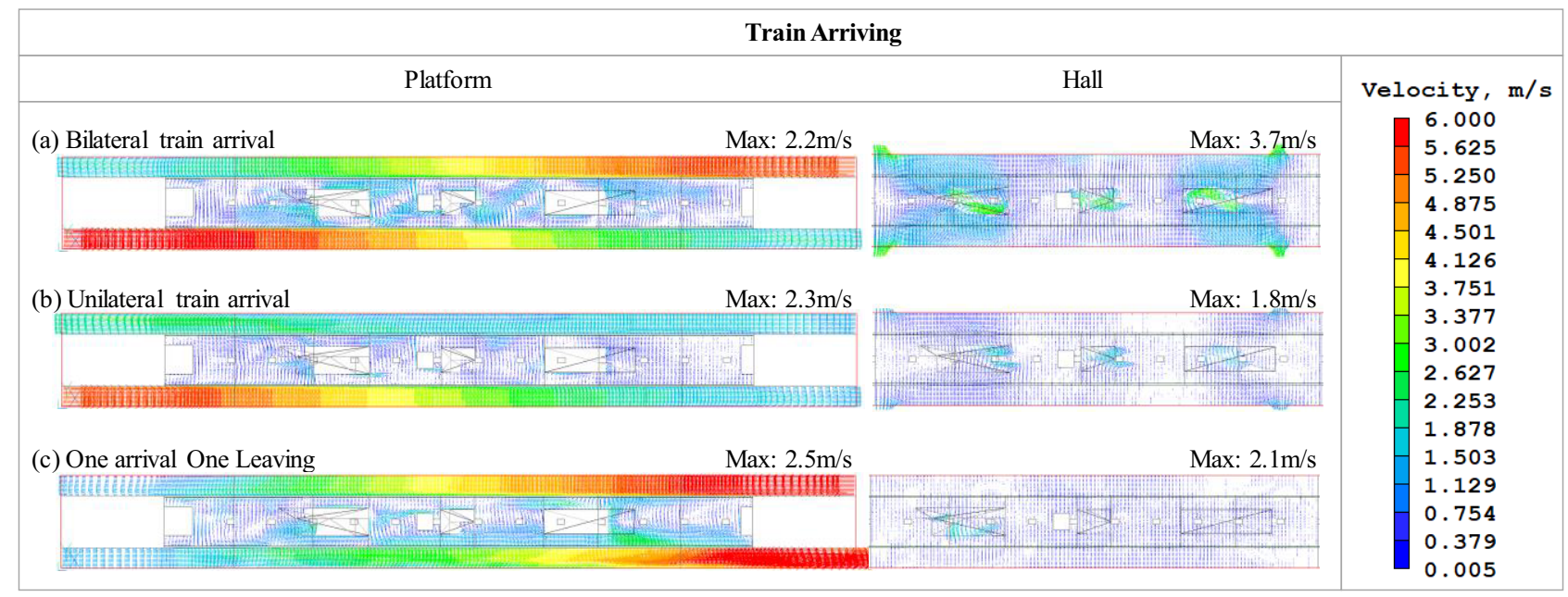

Fig. 6. Velocity distribution - train arriving

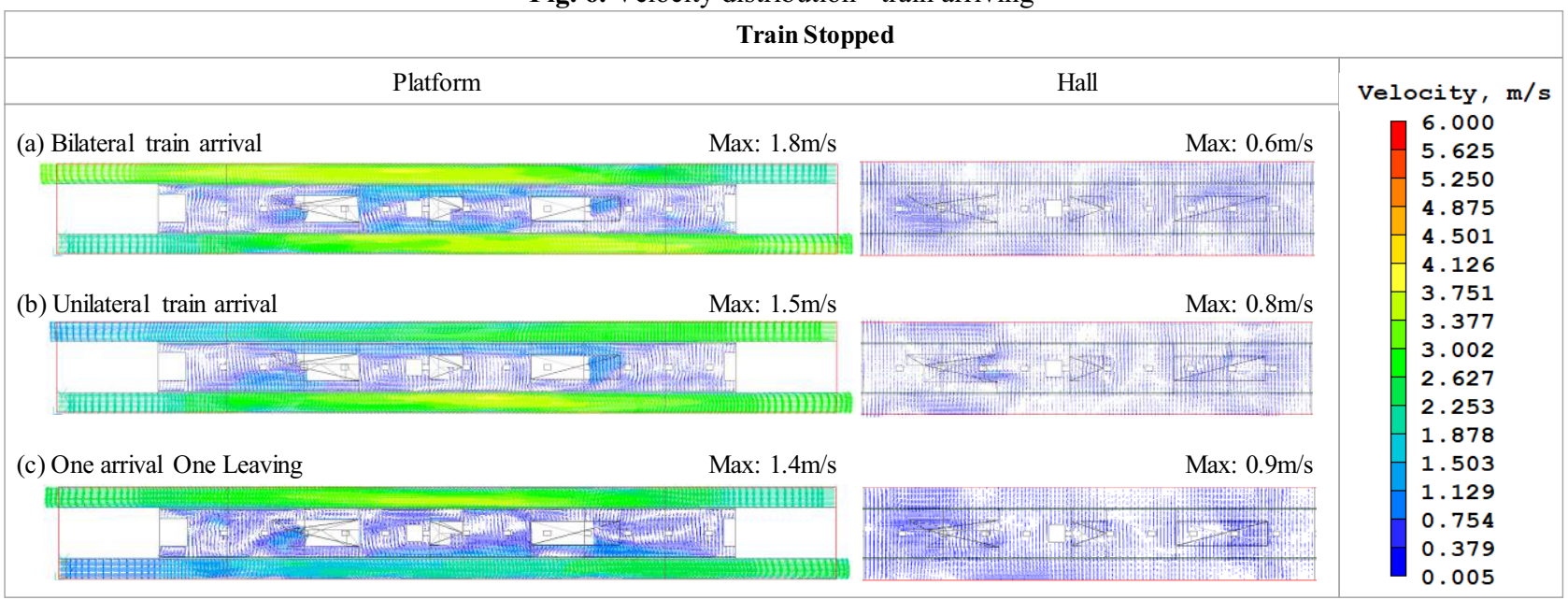

Fig. 7. Velocity distribution - train stopped

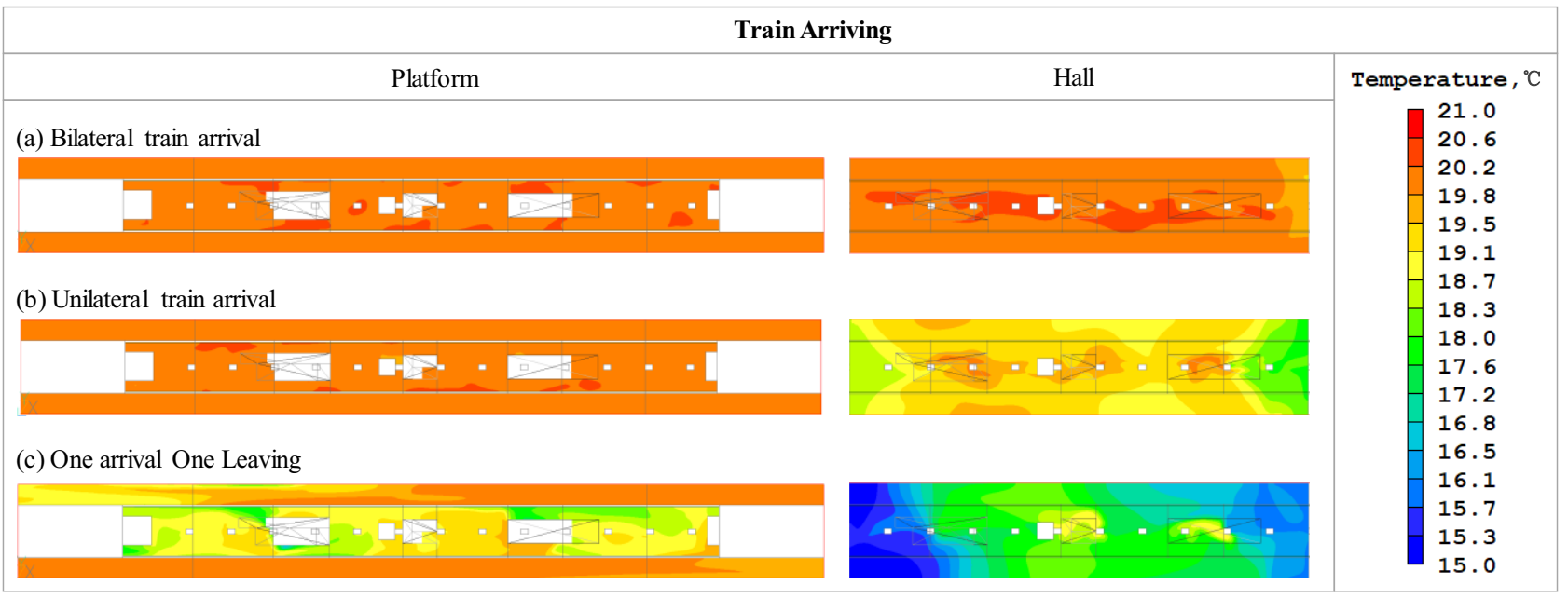

Fig. 8. Temperature distribution - train arriving 


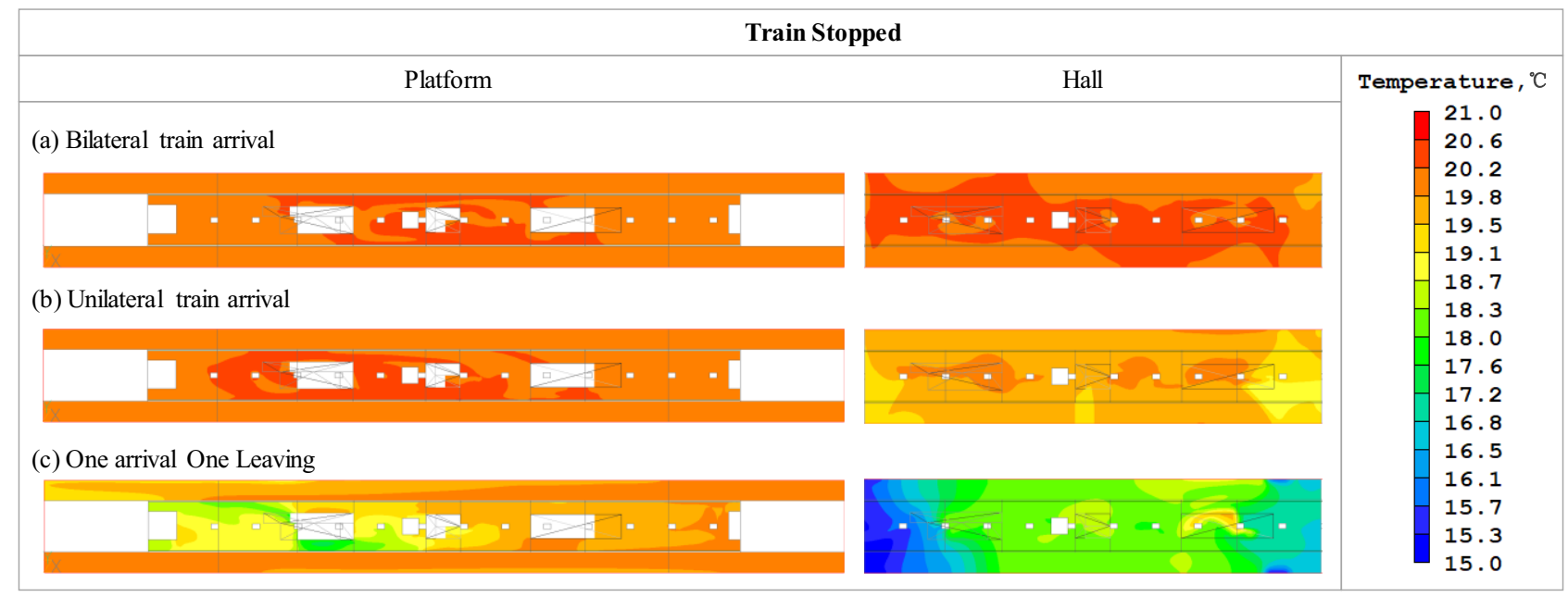

Fig. 9. Temperature distribution - train stopped

\subsection{RWI}

The relationship between the RWI and ASHRAE thermal comfort classification is illustrated in Table 3. The RWI of platform and station hall is summarized for different train arrival patterns. Fig.10 shows the minimum, $1 / 4$ quartile, median, $3 / 4$ quartile and maximum value of RWI for the platform and hall during the period of train arriving and leaving the station.

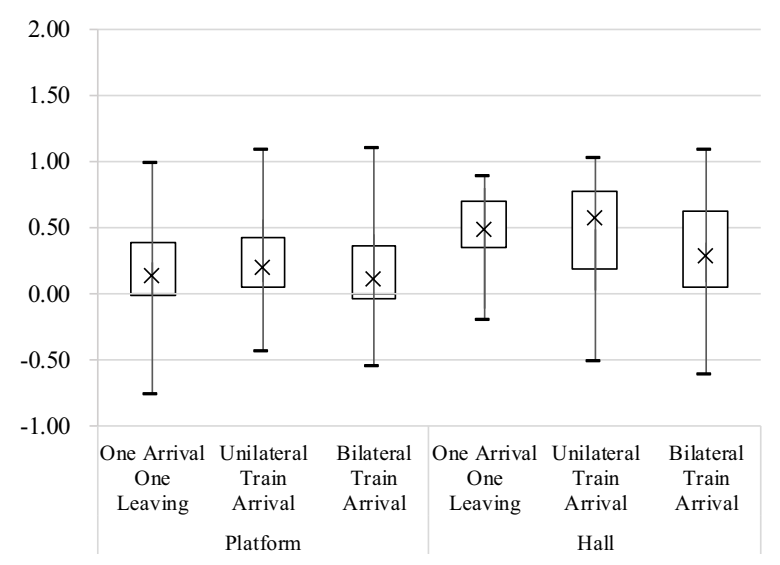

Fig. 10. RWI for the platform and hall

Table 3. RWI and thermal comfort

\begin{tabular}{|c|c|}
\hline ASHRAE Comfort Classification & RWI \\
\hline Warm & 0.25 \\
\hline Slightly Warm & 0.15 \\
\hline Comfortable & 0.08 \\
\hline Slightly Cool & 0 \\
\hline
\end{tabular}

It can be found from Fig.10 that, under the simulated typical condition, the thermal comfort of the platform is better than that of the station hall. The thermal comfort under different train arrival patterns is different, especially for the station hall. Moreover, the piston effect is stronger under the bilateral train arrival pattern, and therefore the thermal comfort of the platform and the station hall is better and more uniform.

In order to better evaluate thermal comfort for passengers, the RWI for the platform as well as hall occupied zone are counted. With regard to the occupied zone for the platform, the RWI is between 0.04 to 0.19 , which is almost within the thermal comfort zone. Nevertheless, the RWI of the occupied zone for the station hall is between 0.15 to 0.52 , indicating that the station hall is relatively warm.

\section{Conclusion}

This paper aims to study the thermal comfort for subway stations with the commonly-applied APSD system under the ventilation mode. In this process, a model for an actual island subway station was established using CFD package PHOENICS. By simulation, the velocity and temperature distribution of the platform as well as the station hall were obtained. Furthermore, Relative Warmth Index (RWI) was applied to assess thermal comfort. The results show that the velocities of the platform and the hall are below $2.5 \mathrm{~m} / \mathrm{s}$ and $3.7 \mathrm{~m} / \mathrm{s}$ respectively. Bilateral train arrival and one arrival one leaving patterns result in stronger piston effect, and therefore, the velocity is higher. Furthermore, it can be concluded from the RWI that the thermal comfort in the platform is better than the hall under the studied typical condition. With regard to the occupied zone, the RWI for the platform is between 0.04 to 0.19 , which is almost within the thermal comfort zone according to the ASHRAE comfort classification. Nevertheless, the RWI of the occupied zone for the station hall is between 0.15 to 0.52 , indicating that the station hall is relatively warm. The outcome of this study provides guidance for the adoption of APSD system for new subway stations and the retrofit for constructed stations. Further study will compare thermal comfort for different types of APSDs. And assessment will be conducted for the whole transitional season instead of the typical conditions. 


\section{References}

1. Annual Report on Urban Rail Transit, 39 (2019)

2. J. Li, X. Li, et al., Build. Sci. 25(12) (2009)

3. S. C. Hu, J. H. Lee, Energy Convers. Manage. 45(5) (2004)

4. Y. Zhang, X. Li, Sustain. Cities Soc. 42 (2018)

5. B. Xu, The study of comfort and energyconsumption of platform bailout doors system and platform screen doors system in subway [D], Tianjin University, 2007.

6. K. Yin, Research on the impact of the automatic sliding door and platform screen door with vents upon the station environment in the side-platform station [D], Tianjin University, 2008.

7. K. Fukuyo, Energy 31(5)(2006)

8. Z. Lin, F. Jiang, et al., Build. Environ. 41(3) (2006)

9. C. Liu, A. Li, et al., Build. Environ. 125(2017)

10. F. E. Camelli, G. Byrne, et al., Tunn. and Undergr. Sp. Tech. 43(2014)

11. M. T. Ke, T. C. Cheng, et al., Build. Environ. 37(11) (2002)

12. M. L. González, M. G. Vega, et al., Tunn. and Undergr. Sp. Tech. 40(2014)

13. A. Khayrullina, B. Blocken, et al., J. Wind Eng. Ind. Aerod. 139(2015)

14. Q. Chen, V. Jan, et al., Energ Buildings. 12(1988)

15. Z. Su, X. Li, Sustain. Cities Soc. 52 (2020)

16. Y. Wang, X. Li, Sustain. Cities Soc. 38(2018)

17. X. Zhang, J. Ma, et al., Build. Environ. 152(2019)

18. J. Ma, X. Zhang, et al., Build. Environ. 143(2018)

19. Subway Environmental Design Handbook, 197 